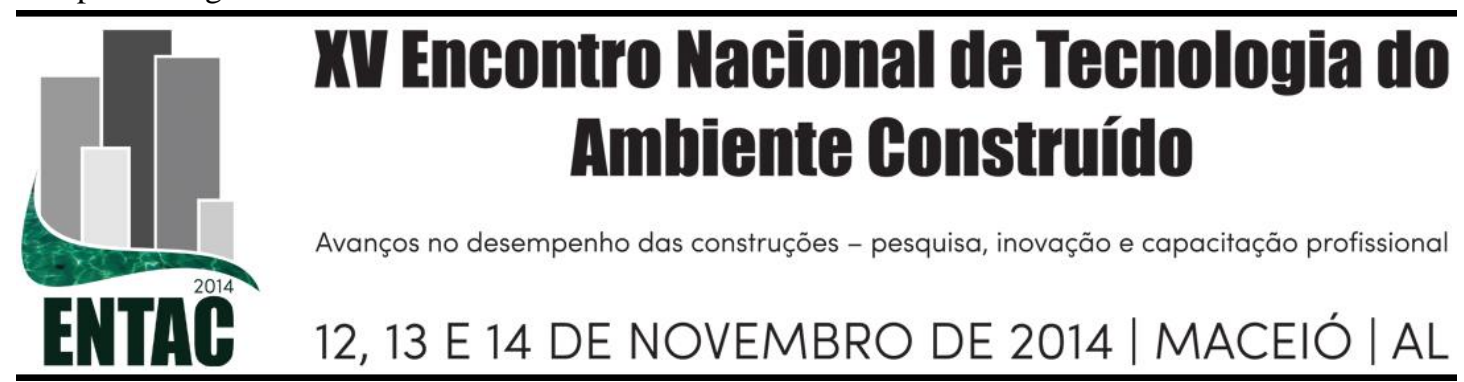

\title{
PROPOSTA DE HABITAÇÃO COM REÚSO E RECICLAGEM DE MATERIAIS E RESÍDUOS INDUSTRIAIS
}

\author{
ALMEIDA, Mariana Marques (1); BASTOS, Pedro Kopschitz Xavier (2);
}

(1) Universidade Federal de Juiz de Fora (UFJF), e-mail: mariana.mma@gmail.com (2) Universidade Federal de Juiz de Fora (UFJF), e-mail: pedrokop@terra.com.br

\begin{abstract}
RESUMO
A montagem de componentes construtivos a partir de resíduos industriais reutilizados tem enorme potencial na área de habitação. O presente trabalho apresenta algumas ideias para fundação, fechamento de parede e cobertura de uma edificação. As soluções desenvolvidas são resultados finais de uma pesquisa de Iniciação Científica que utilizou como métodos: a) consultas bibliográficas; b) pesquisas de campo, com o intuito de identificar os principais resíduos gerados na atividade industrial de Juiz de Fora - MG e região; c) análise dos resíduos identificados e seleção daqueles passíveis de uso em habitação; d) realização de um projeto de arquitetura com os resíduos selecionados. Foram utilizados recipientes plásticos, restos de estacas, resíduos de construção civil (cerâmica, concreto e argamassa), paletes de madeira, tapumes metálicos e escoras de eucalipto. O conjunto proposto ainda não foi construído em escala real. O trabalho mostra uma proposta de técnica construtiva, simples e capaz de alcançar diferentes classes sociais, principalmente as de menor poder aquisitivo. Deseja-se, também, que o projeto ajude a diminuir a poluição ambiental causada por resíduos descartados irregularmente e a reduzir o consumo de energia e de recursos naturais não renováveis, contribuindo, assim, para a preservação do meio ambiente.
\end{abstract}

Palavras-chave: Construção Civil, Habitação, Reúso de Resíduos Industriais.

\begin{abstract}
The reuse of industrial waste in construction business is an outstanding opportunity to protect the environment, decreasing the extraction of mineral resources and waste disposal in landfills. The development of construction components from industrial waste can have great potential in housing projects. This paper presents several applications of industrial waste produced in high scale by manufacturing zones around the city of Juiz de Fora, Minas Gerais, Brazil, which have not yet been experimented in real situations. The solutions proposed embrace foundation, walls and roof, including tips for project implementation.
\end{abstract}

Keywords: Construction, Housing, Reuse of industrial waste

\section{INTRODUÇÃ̃O}

Atualmente, com a necessidade de ações de preservação do planeta, existe uma forte tendência à reciclagem e reúso de materiais em diversos setores de atividades humanas. $\mathrm{O}$ presente trabalho aborda o reúso de resíduos industriais em componentes da construção civil para habitação. As sobras de diversas indústrias, como perfís metálicos, chapas, correias, bobinas e recipientes podem ser utilizadas na construção, por exemplo, de paredes, pisos, escadas e pilares em uma construção. 
O presente trabalho insere-se no contexto da Política Nacional de Resíduos Sólidos (BRASIL, Lei ${ }^{\mathrm{o}} 12.305,2010$ ), em vigor desde 2010, onde estão definidos:

- "Ciclo de vida do produto: série de etapas que envolvem o desenvolvimento do produto, a obtenção de matérias-primas e insumos, o processo produtivo, o consumo e a disposição final";

- "Destinação final ambientalmente adequada: destinação de resíduos que inclui a reutilização, a reciclagem, a compostagem, a recuperação e o aproveitamento energético ou outras destinações admitidas pelos órgãos competentes...".

- "Logística reversa: instrumento de desenvolvimento econômico e social caracterizado por um conjunto de ações, procedimentos e meios destinados a viabilizar a coleta e a restituição dos resíduos sólidos ao setor empresarial, para reaproveitamento, em seu ciclo ou em outros ciclos produtivos, ou outra destinação final ambientalmente adequada;"

- "Reutilização: processo de aproveitamento dos resíduos sólidos sem sua transformação biológica, física ou físico-química, observadas as condições e os padrões estabelecidos pelos órgãos competentes...".

A principal razão para o reúso (ou reutilização) de materiais ou uso de materiais reciclados é beneficiar o meio ambiente (ADDIS, 2010). Na construção civil, são reduzidos os impactos ambientais decorrentes da extração de matéria-prima diretamente do ambiente e a extração de recursos naturais não renováveis. Também é evitado o envio de materiais passíveis de reúso para aterros, diminuindo a poluição (ADDIS, 2010). Portanto, é importante o desenvolvimento de ideias alternativas que atendam a essas necessidades.

Além de ganhos ambientais, o reaproveitamento de resíduos industriais como componentes construtivos pode representar ganhos sociais. Um dos benefícios é a diminuição do custo da construção (ADDIS, 2010), possibilitando projetos voltados para habitação de interesse social, visando redução do déficit habitacional, principalmente em países subdesenvolvidos e em desenvolvimento. Ao mesmo tempo, o reúso de resíduos em habitações pode ser o partido adotado, também, em construções de alto e médio padrões.

A presente pesquisa teve como objetivos selecionar resíduos e desenvolver ideias de reúso como componentes para construção de uma habitação, realizando, também, e o projeto de uma residência. A partir de buscas em indústrias da região de Juiz de Fora, Minas Gerais, foram identificados e selecionados aqueles que existem em grande quantidade e que seriam passíveis de reúso para os objetivos pretendidos. Neste trabalho apresenta-se o desenvolvimento dos seguintes componentes de uma habitação: fundação, estrutura (pilar), fechamento de parede e cobertura, com sugestões de montagem. Ressalta-se que os modelos de montagem sugeridos não foram, ainda, objeto de análise experimental em escala real.

\section{REÚSO DE RESÍDUOS INDUSTRIAIS E DE MATERIAIS DE CONSTRUÇÃO}

O cenário onde se justifica a opção de reúso de materiais de construção envolve, entre outros, os seguintes aspectos: 
- A construção civil representa boa parcela da atividade econômica do Brasil e isto quer dizer, também, extração de grande quantidade de matéria-prima da natureza.

- O déficit habitacional brasileiro insiste em permanecer entre cinco e seis milhões de moradias (IPEA, 2013), independentemente dos altos e baixos da economia crescemos significativamente nos anos 90 e na primeira década do segundo milênio e voltamos praticamente à estagnação nos últimos quatro anos. As iniciativas governamentais não levam em conta, de forma adequada, a complexidade social e demográfica do país. Estabelecem-se metas que não resolvem um problema crônico.

- Falsa ideia, por parte da sociedade, de projetistas e de construtores, de que os recursos naturais são inesgotáveis, o que alimenta a cultura do desperdício.

- Falta de cultura de preservação de construções antigas e em perfeito estado de conservação, ocasionando excesso de demolições, pressionadas pela especulação imobiliária.

Para cada um desses aspectos o reúso de materiais aparece como boa alternativa de solução parcial dos problemas mencionados, conforme mostra a Tabela 1.

Tabela 1 - Reúso de materiais como solução para problemas da construção habitacional no Brasil.

\section{Aspectos do cenário brasileiro urbano de construção habitacional}

\begin{tabular}{ll}
\hline $\begin{array}{l}\text { Atividade industrial expressiva e } \\
\text { exploração de matérias-primas. }\end{array}$ & Redução do volume de materiais retirados da natureza. \\
$\begin{array}{l}\text { Déficit habitacional. } \\
\text { Cultura do desperdício. }\end{array}$ & $\begin{array}{l}\text { Construção de habitações de baixo custo. } \\
\text { Promover a cultura de que se deve economizar, } \\
\text { reaproveitar, reciclar e reutilizar. }\end{array}$ \\
$\begin{array}{l}\text { Demolições em excesso, } \\
\text { pressionadas pela especulação } \\
\text { imobiliária. }\end{array}$ & $\begin{array}{l}\text { Atrelar-se a essa realidade, para fomentar o setor de } \\
\text { consumo de materiais reutilizáveis em bom estado - } \\
\text { tijolos, portas, janelas, telhas, portões, perfis, tubos, etc. }\end{array}$ \\
\hline
\end{tabular}

Reúso de materiais permite:

Redução do volume de materiais retirados da natureza.

Construção de habitações de baixo custo. reaproveitar, reciclar e reutilizar. consumo de materiais reutilizáveis em bom estado -

Demolições com separação dos materiais por classes, a fim de descartá-los corretamente, comercializá-los como resíduos ou mesmo reutilizá-los, costumam ser raras nas cidades brasileiras em que não existe política pública para os resíduos sólidos. A Figura 1 mostra um caso isolado na cidade de Juiz de Fora, onde o poder público não exige a demolição seletiva e não oferece estrutura para receber os resíduos separados para reciclagem. 


\section{Figura 1 - Caso raro de demolição de residência com retirada cuidadosa dos materiais para reúso em Juiz de Fora.}
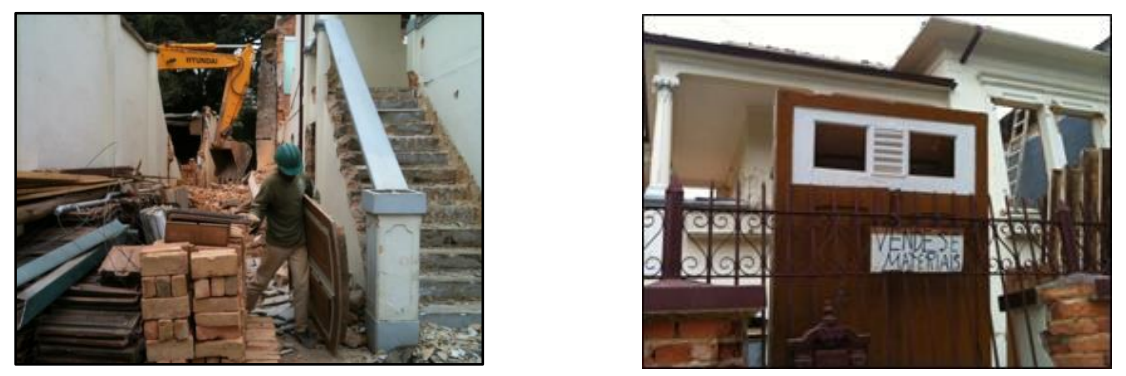

É importante mencionar, também, que tanto a reciclagem quanto o reúso de materiais, para serem considerados eficazes do ponto de vista ambiental, devem ser objeto de uma Análise de Ciclo de Vida, considerando seus impactos (emissão de $\mathrm{CO}_{2}$ e consumo de energia, por exemplo) na extração de matéria-prima, transporte, produção, aplicação, manutenção, demolição e descarte (ou reúso reciclagem). Esta análise não será objeto do presente trabalho.

\section{METODOLOGIA}

Para atingir os objetivos propostos, a metodologia utilizada consistiu em pesquisa bibliográfica de exemplos de reúso de resíduos em habitações e envio de questionário a indústrias da região de Juiz de Fora, potenciais geradoras de resíduos como chapas, perfis, tubos, estacas e recipientes. O questionário continha perguntas sobre quantidade gerada, características físicas (volume, peso, forma), origem, material constituinte e tipo de descarte. Para seleção das indústrias foi utilizado o Cadastro Industrial 2011 da FIEMG - Federação das Indústrias do Estado de Minas Gerais. Com a análise dos dados obtidos foram desenvolvidas as propostas de alternativas construtivas e o projeto de uma residência com a reutilização dos resíduos selecionados.

Os resíduos foram selecionados de modo que apresentassem o maior número possível dos seguintes requisitos de qualidade:

- Facilidade de aplicação, sem necessidade de mão-de-obra especializada, como soldador, torneiro mecânico;

- Mínima necessidade de tratamento prévio, como cortes, lixamento, soldas, limpeza com solventes, etc.

- Facilidade de retirada/desmontagem para novos reúsos, em caso de demolição da construção;

- Não ser causador de poluição ou apresentar possibilidade de absorção pelo ambiente;

- Custo (aquisição + aplicação) não superior ao de um componente convencional.

\section{RESULTADOS}

O número de questionários respondidos foi muito pequeno - apenas quatro, de 36 enviados. Acredita-se que haja pouca motivação em torno do tema por parte das indústrias locais, ou que haja receio de fornecer informações sobre resíduos, quando não são seguidas normas ambientais. Com isso, a seleção de resíduos para a pesquisa passou a ser baseada mais fortemente: a) na observação da tecnologia de construção local, onde há predominância de sistemas construtivos baseados em estrutura de concreto armado, 
uso intensivo de fôrmas de madeira, materiais cerâmicos e argamassas, apenas para citar os mais representativos em volume. Na cidade de Juiz de Fora são geradas de mil toneladas diárias de resíduos de construção civil (PREFEITURA DE JUIZ DE FORA, 2010), destinadas ao aterro sanitário, sem reciclagem; b) nos resíduos presentes em depósitos de vendas de materiais usados.

$\mathrm{Na}$ Tabela 2 são apresentados os resíduos selecionados e as respectivas possibilidades de reúso/aplicação: 
Tabela 2 - Resíduos selecionados e posibilidades de reúso.

\begin{tabular}{ll}
\hline RESÍDUO & REÚSO/APLICAÇÃO \\
\hline $\begin{array}{l}\text { Restos de estacas prémoldadas de concreto para } \\
\text { fundação profunda (Figura 2). }\end{array}$ & Pilar de reforço de canto de parede. \\
$\begin{array}{l}\text { Recipientes plásticos - bombonas (Figura 3). } \\
\text { Paletes de madeira (Figura 4). }\end{array}$ & $\begin{array}{l}\text { Forma para fundação rasa - bloco } \\
\text { isolado. } \\
\text { Painel de fechamento de cômodo } \\
\text { (paredes externas e internas) }\end{array}$ \\
$\begin{array}{l}\text { Entulho de obra (concreto, cerâmica, } \\
\text { argamassa) reciclado como agregado (Figura 4). } \\
\text { Tapumes descartados de canteiros de obras } \\
\text { construídos com telhas metálicas (Figura 5). } \\
\text { Escoras de eucalipto. }\end{array}$ & $\begin{array}{l}\text { Cobertura. } \\
\text { Contêinier metálico oriundo de transporte de } \\
\text { cargas (Figura 5). }\end{array}$ \\
\hline
\end{tabular}

Figura 2 - Restos de estacas prémoldadas de concreto. Reúso como pilares.
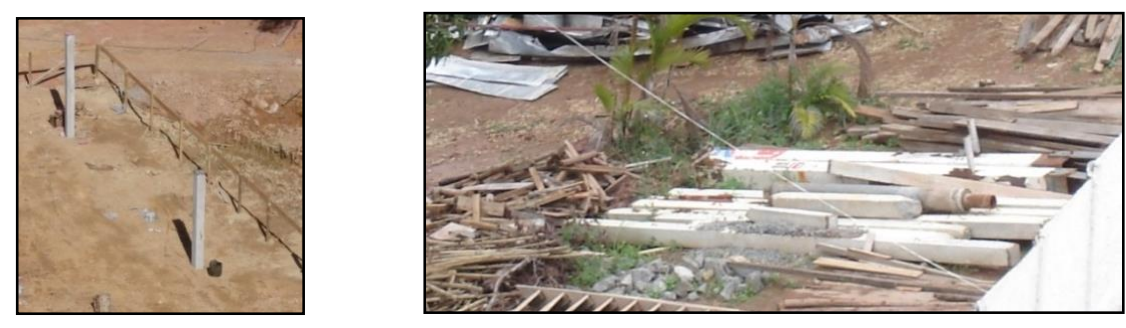

Figura 3 - Bombona plástica. Reúso como fôrma para bloco de fundação.
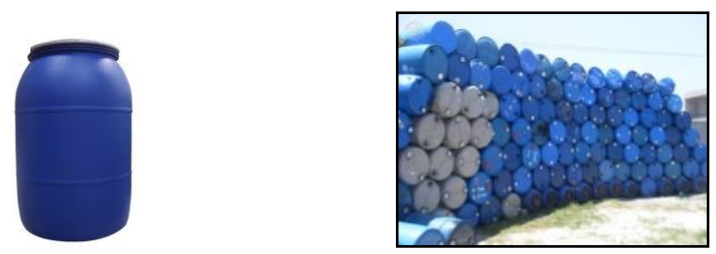

Figura 4 - Paletes de madeira e agregado reciclado de resíduo de construção civil para reúso como painéis de fechamento e enchimento para paredes de uma habitação, respectivamente.
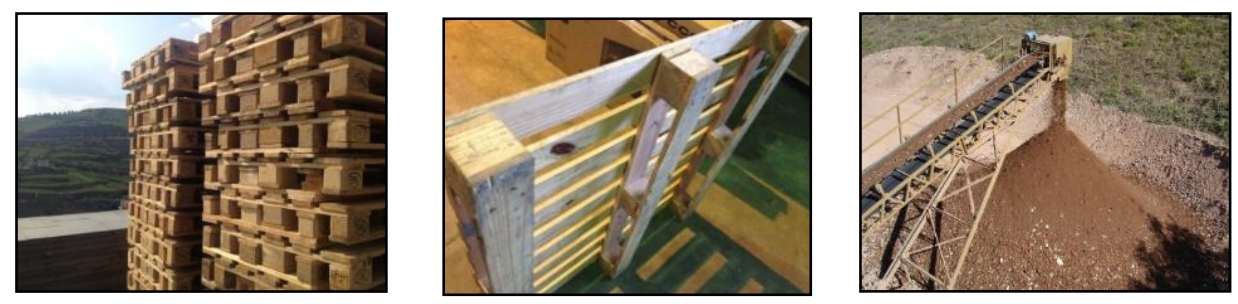
Figura 5 - Tapume de obra de telha de alumínio para reúso como cobertura e contêineres metálicos para reúso como paredes ou cômodos inteiros.
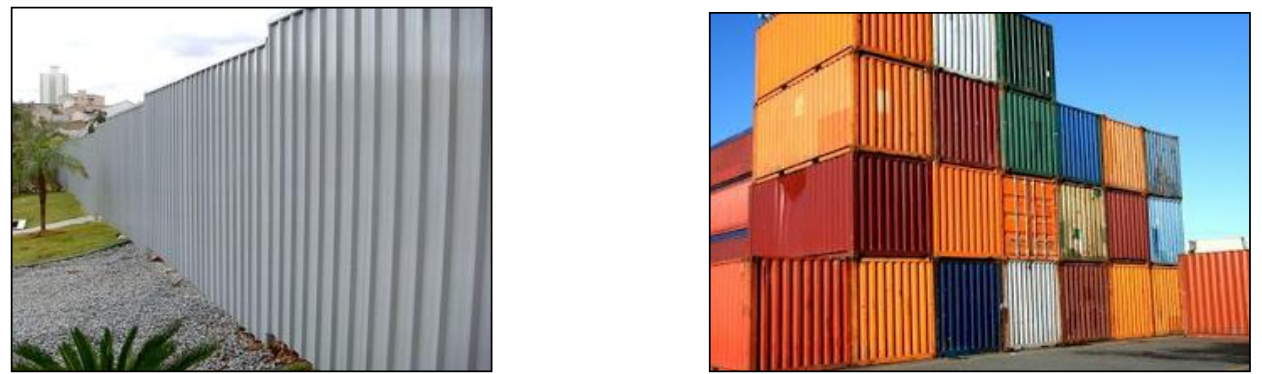

No Quadro 1 são assinalados os requisitos de qualidade que os materiais e resíduos podem apresentar, a depender de seu estado de conservação e de características específicas, como dimensões.

Quadro 1 - Cruzamento materiais selecionados $\mathrm{x}$ requisitos de qualidade.

\begin{tabular}{|l|l|l|l|l|l|}
\cline { 2 - 6 } \multicolumn{1}{c|}{} & \multicolumn{5}{c|}{ REQUISITOS DE QUALIDADE } \\
\cline { 2 - 6 } \multicolumn{1}{c|}{} & $\begin{array}{l}\text { Fácil } \\
\text { aplicação }\end{array}$ & $\begin{array}{l}\text { Mínima } \\
\text { necessidade de } \\
\text { tratamento prévio }\end{array}$ & $\begin{array}{l}\text { Fácil } \\
\text { desmontagem }\end{array}$ & $\begin{array}{l}\text { Não causa } \\
\text { poluição }\end{array}$ & $\begin{array}{l}\text { Custo } \\
\text { baixo }\end{array}$ \\
\hline $\begin{array}{l}\text { Restos de } \\
\text { estacas de } \\
\text { concreto. }\end{array}$ & $\checkmark$ & $\checkmark$ & $\checkmark$ & $\checkmark$ \\
\hline $\begin{array}{l}\text { Recipiente } \\
\text { plástico }\end{array}$ & $\checkmark$ & $\checkmark$ & $\checkmark$ & $\checkmark$ & $\checkmark$ \\
\hline $\begin{array}{l}\text { Paletes de } \\
\text { madeira }\end{array}$ & $\checkmark$ & $\checkmark$ & $\checkmark$ & $\checkmark$ \\
\hline $\begin{array}{l}\text { Agregado } \\
\text { reciclado }\end{array}$ & $\checkmark$ & $\checkmark$ & $\checkmark$ & $\checkmark$ & $\checkmark$ \\
\hline $\begin{array}{l}\text { Telha } \\
\text { metálica } \\
\text { descartada }\end{array}$ & $\checkmark$ & $\checkmark$ & $\checkmark$ & $\checkmark$ & $\checkmark$ \\
\hline $\begin{array}{l}\text { Escoras de } \\
\text { eucalipto }\end{array}$ & $\checkmark$ & $\checkmark$ & $\checkmark$ & $\checkmark$ & $\checkmark$ \\
\hline Contêiner & & & & $\checkmark$ & $\checkmark$ \\
\hline
\end{tabular}

\section{PROPOSTAS DE MONTAGEM}

\subsection{Recipiente plástico como fôrma para fundação}

A proposta constitui-se no reúso de bombona plástica de 50 litros ou similar como fôrma para bloco isolado de fundação em terrenos firmes na superfície (Figura 6). Tratase de um reúso que evita o uso de madeira. Cada caso deverá levar em conta as cargas atuantes, a resistência do terreno e a área da base da bombona, que poderá ser aberta no fundo para melhor contato como o solo, evitando deslizamentos em terrenos inclinados. Após ser utilizada como forma, a ideia é dar um segundo ou mais usos à bombona. Quando não for mais possível o reúso, seria descartada como plásticos para reciclagem. 


\subsection{Resto de estaca como pilar}

O processo de cravação de estacas prémoldadas de concreto em grandes edifícios gera sobras, com pedaços relativamente grandes, de acordo com as caraterísticas do terreno de cada obra. As estacas de seção $20 \mathrm{~cm}$ x $20 \mathrm{~cm}$, ou próximas, encaixadas nos blocos de fundação, podem servir como pilares para uma construção baixa (Figura 6), sem compromisso estrutural, apenas como reforço de canto dos cômodos. Provavelmente, os trechos reutilizados não terão a altura exata do pé direito da edificação e, portanto, será necessária a realização de emendas ou cortes.

Figura 6 - Reúso de bombona plástica como fôrma de bloco de fundação e trecho de estaca de concreto como pilar.

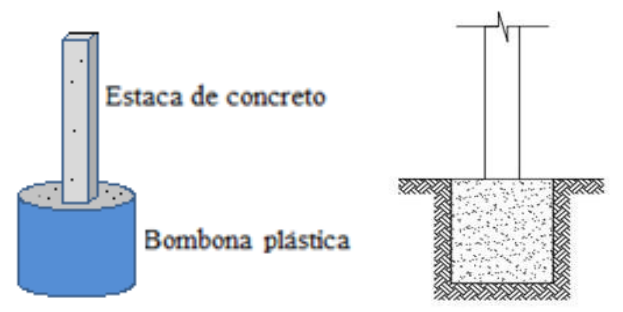

\subsection{Paletes de madeira como envelope da edificação e divisórias internas}

Foi idealizado um "sanduíche" formado por painéis duplos de paletes de madeira preenchidos com concreto de resíduos de construção civil (cerâmica, concreto e argamassa) - Figura 7. Evitou-se conceber uma casa apenas de madeira, que poderia ser considerada frágil e pouco durável. Na Figura 8 pode-se observar o detalhe do encaixe dos painéis de fechamento com o pilar de canto dos cômodos. No trabalho de Baungarten (2012), os paletes foram todos desmontados para refazer painéis inteiriços. A presente proposta consiste em desmontar apenas parte deles e usar as réguas resultantes da desmontagem para formar uma veneziana na face externa das paredes (Figura 9), com a finalidade de evitar penetração de água de chuva. O lançamento do concreto deve ser feito diretamente nos painéis de palete já fixados, com cuidados especiais para evitar vazamento. O acabamento da parte superior da parede pode ser visto na Figura 11.

Figura 7 - Parede de camada dupla de paletes de madeira - vista em planta.

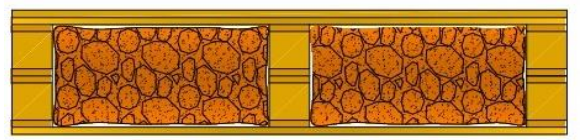

Figura 8 - Detalhe do encaixe do painel de palete no pilar de estaca de concreto, com utilização de cantoneiras metálicas para fixação - vista em planta.

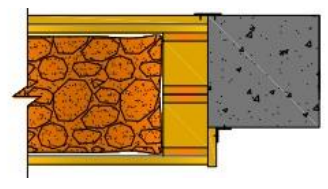


Figura 9 - Parede de camada dupla de paletes de madeira preenchida com concreto de resíduo de construção civil reciclado - vista em corte.

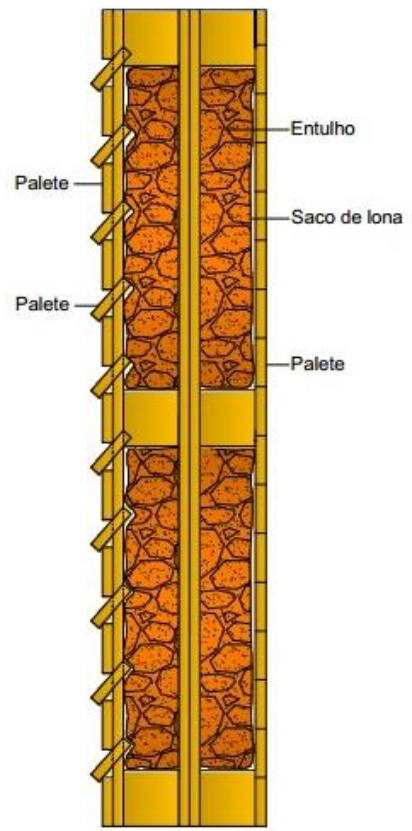

\subsection{Telhado}

Pensou-se em executar a cobertura com reaproveitamento de tapumes de obras cercadas com telhas metálicas. Para melhoria do conforto térmico, réguas de paletes desmontados podem compor o forro sob as telhas (Figura 10 e Figura 11).

Figura 10 - Detalhe do telhado.

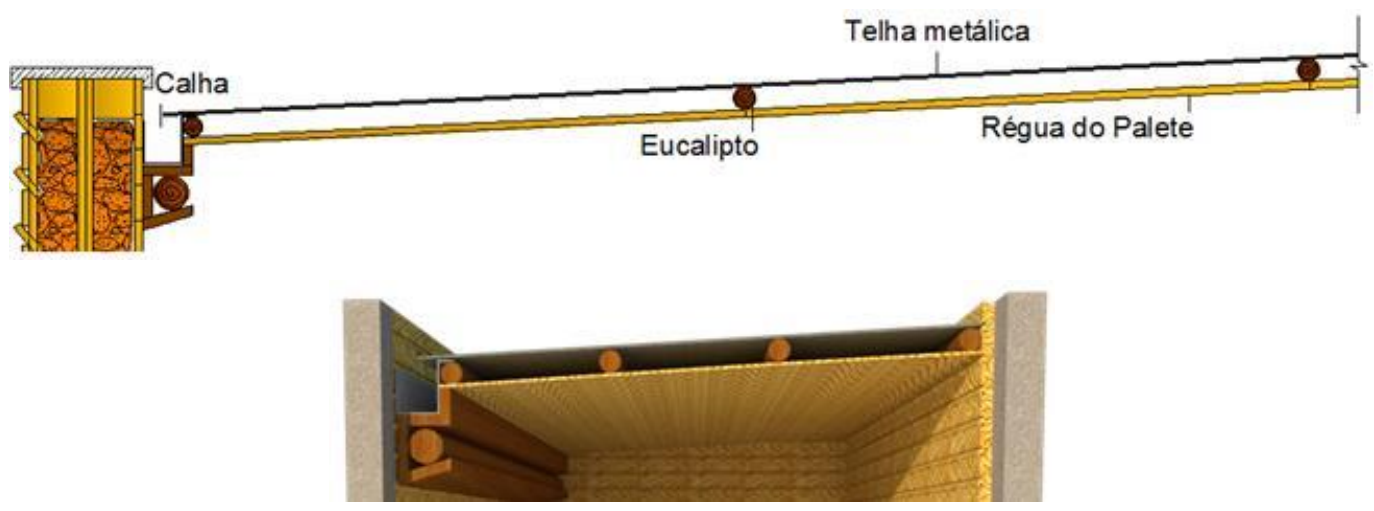

Figura 11 - Detalhe do acabamento parede/cobertura

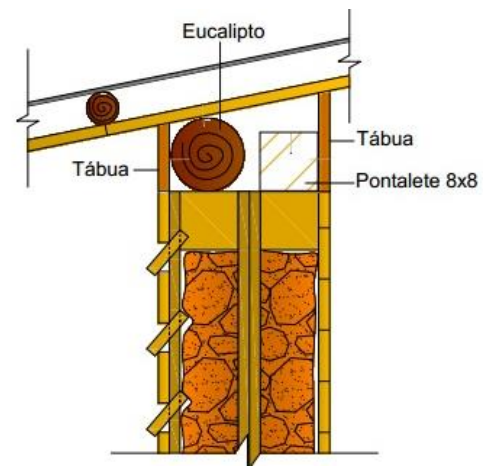




\subsection{Contêiner}

Além dos painéis de palete, optou-se por criar um cômodo de contêiner metálico, resíduo descartado pelo setor de transporte de cargas. Após alguns anos de uso, eles acabam sendo inutilizados. Os contêineres são caixas de aço com dimensões fixas. $\mathrm{Na}$ presente pesquisa adotou-se o contêiner de $6 \mathrm{~m}$ de comprimento e 2,5 $\mathrm{m}$ de largura. Por serem de aço, essas peças conduzem muito calor e necessitam de tratamento térmico, principalmente na cobertura. A solução encontrada foi o emprego de lona plástica e argila expandida sobre o teto. Optou-se por utilizar o contêiner apenas na área molhada da casa, de modo a construir uma única parede hidráulica.

\section{PROJETO ARQUITETÔNICO}

Foi desenvolvido o projeto arquitetônico de uma casa de um pavimento, com um quarto, uma sala, um banheiro, cozinha e área de serviço, totalizando $50 \mathrm{~m}^{2}$ de área construída e $42 \mathrm{~m}^{2}$ de área útil, mostrado na Figura 12.

Figura 12 - Projeto arquitetônico - casa a ser construída com reúso de resíduos.

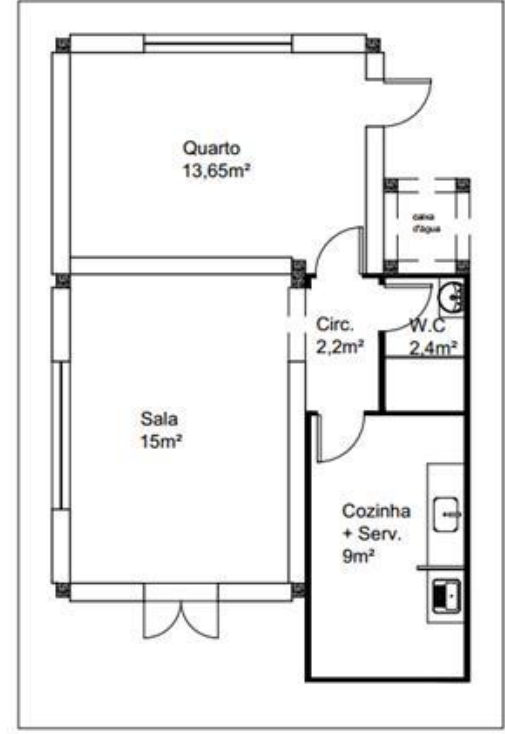

Contêiner

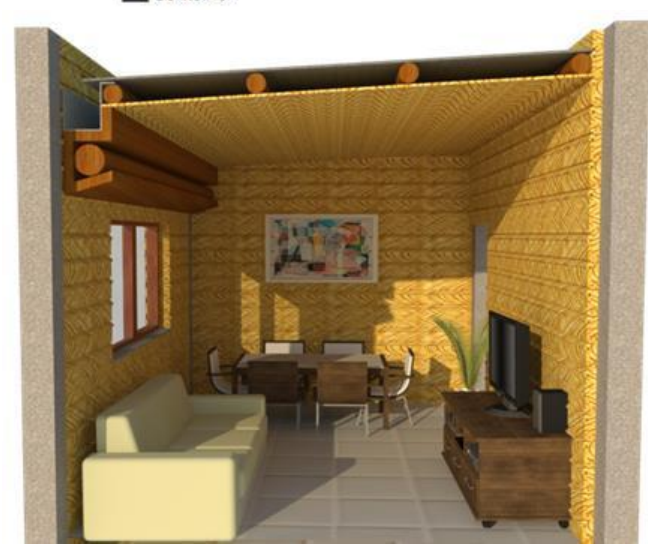

Sala - perspectiva
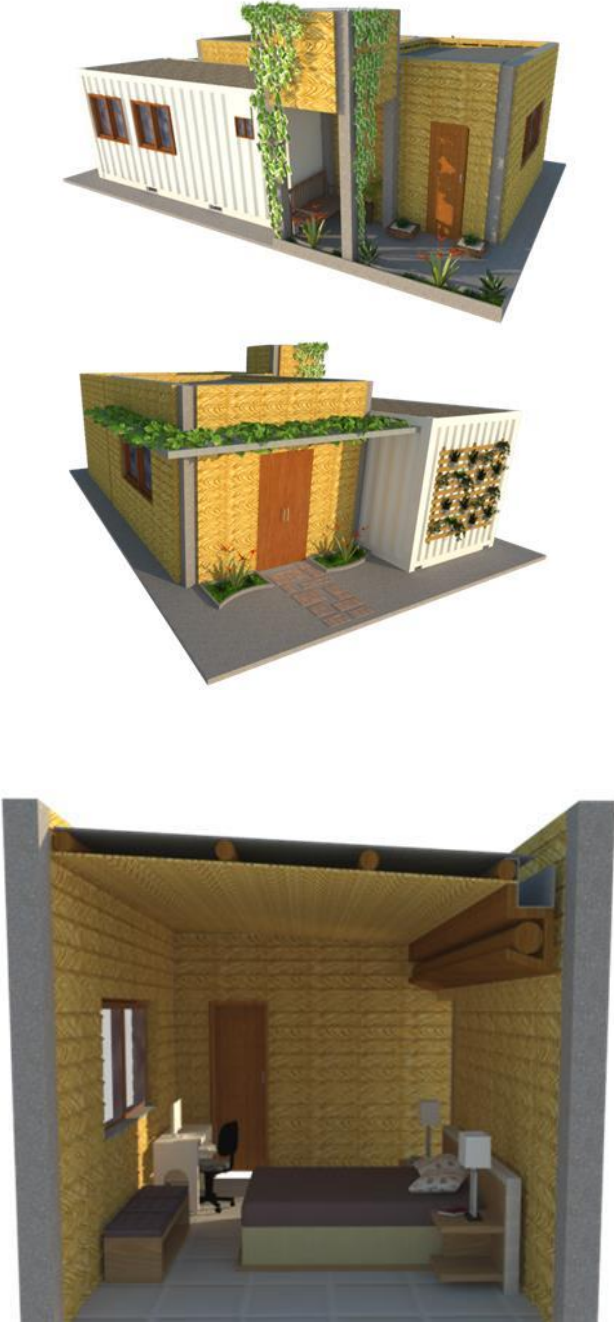

Sala - perspectiva 


\section{CONCLUSÃO}

Como resultados principais, foram apresentados resíduos comumente encontrados na região de Juiz de Fora, alguns deles também em outros centros urbanos do Brasil, como recipientes plásticos, restos de estacas, resíduos de construção civil, paletes de madeira, telhas metálicas e contêineres, com propostas de montagem de uma habitação a partir do reúso destes resíduos. Existem outras inúmeras outras possibilidades e, ressalta-se, cada proposta deve passar, antes da aplicação real, pela montagem de um protótipo e por análise de desempenho, considerando a recente publicação da norma ABNT NBR 15.575:2013 Edificações Habitacionais - Desempenho. Essa análise é essencial e poderá complementar a presente pesquisa, assim como o desenvolvimento de componentes para outras partes de uma habitação como pisos, escadas, portas e janelas, aqui não apresentadas. Acredita-se que as montagens mostradas estejam ao alcance de usuários de diferentes classes, principalmente os de menor poder aquisitivo, dada a simplicidade da técnica construtiva proposta e da abundância local dos resíduos a serem reutilizados.

\section{AGRADECIMENTOS}

À Propesq/UFJF pela oportunidade de pesquisa concedida com o Programa de Iniciação Científica BIC/UFJF 2012/2013.

\section{REFERENCIAS}

ADDIS B. Reúso de materiais e elementos da construção / Bill Addis; tradução Christina Del Posso. São Paulo: Editora Oficina de Textos. (2010)

ASSOCIAÇÃO BRASILEIRA DE NORMAS TÉCNICAS (ABNT). NBR-15.575.2013: Edificações Habitacionais - Desempenho. 2013.

BAUngarten C., MELlO N.V.C., ALMEIDA J.S. Casa Palete. $1^{\circ}$ Seminário Nacional de Construções Sustentáveis, 27 e 28 de novembro, Passos Fundos. (2012)

BRASIL, Lei $\mathrm{n}^{\circ}$ 12.305, de 2 de agosto de 2010. Institui a Política Nacional de Resíduos Sólidos; altera a Lei no 9.605, de 12 de fevereiro de 1998; e dá outras providências. Disponível em: <http://www.planalto.gov.br/ccivil_03/_ato2007-2010/2010/lei/112305.htm> Acesso em: 03 jul 2013.

IPEA. Estudo aponta redução no déficit habitacional no país. Disponível em http://www.ipea.gov.br/portal/index.php?option=com_content\&view=article\&id=20656. Acessado em: 19/05/2014.

PREFEITURA DE JUIZ DE FORA. Plano Integrado de Gerenciamento de Resíduos de Construção Civil de Juiz de Fora. Juiz de Fora, Prefeitura de Juiz de Fora, 2010. 